\title{
What Is Missing in Amphibian Decline Research: Insights from Ecological Sensitivity Analysis
}

\author{
ROMAN BIEK, ${ }^{*}$ W. CHRIS FUNK, $†$ BRYCE A. MAXELL,${ }^{*} \ddagger$ AND L. SCOTT MILLS* \\ *Wildlife Biology Program, School of Forestry, University of Montana, Missoula, MT 59812, U.S.A. \\ †Organismal Biology and Ecology Program, Division of Biological Sciences, University of Montana, \\ Missoula, MT 59812, U.S.A.
}

\begin{abstract}
Inventory, monitoring, and experimental studies have been the primary approaches for documenting and understanding the problem of amphibian declines. However, little attention bas been given to placing buman-caused perturbations affecting one or more life-history stages in the context of the overall population dynamics of particular species. We used two types of ecological sensitivity analysis to determine which vital rates have the strongest influence on the population dynamics of western toads (Bufo boreas), red-legged frogs (Rana aurora), and common frogs (Rana temporaria), pond-breeding amphibians that have declined in all or portions of their ranges. Our results suggest that post-metamorphic vital rates and highly variable vital rates both have a strong influence on the population dynamics of these species and therefore deserve more research and management attention. Ecological sensitivity analysis should be more widely applied to the issue of amphibian declines in order to identify the most plausible mechanisms of decline and prioritize which lifebistory stages should be the focus of research and management efforts. Future experimental studies of perturbations in one or more life-history stage should attempt to link the magnitude of the perturbation measured with the overall population-level consequences. Finally, current research, inventory, and monitoring efforts should be supplemented with demographic studies so that quantitative analyses can be applied to a wider range of species and life-bistory groups.
\end{abstract}

Investigación sobre la Disminución de Anfibios: Comprensión del Análisis de Sensibilidad Ecológica

Resumen: Los estudios de inventario, monitoreo y experimentales ban sido las principales estrategias para documentar y entender el problema de la disminución de los anfibios. Sin embargo, se ha puesto poca atención en colocar a las perturbaciones causadas por bumanos en uno o más estadios de las bistorias de vida en el contexto de la dinámica poblacional general de ciertas especies en particular. Empleamos dos tipos de análisis de sensibilidad ecológica para determinar que tasas vitales tenían mayor influencia en las dinámicas poblacionales de sapos del oeste (Bufo boreas), de la rana de patas rojas (Rana aurora) y la rana común (Rana temporaria), anfibios que se reproducen en charcas y que han disminuido en todo o en parte de sus rangos. Nuestros resultados sugieren que tanto la supervivencia de adultos como las tasas vitales altamente variables tienen influencias fuertes en la dinámica poblacional de estas especies y, por lo tanto, requieren una mayor atención en su investigación y manejo. El análisis de sensibilidad ecológica debería ser aplicado más ampliamente a temas de disminución de anfibios para poder identificar los mecanismos más plausibles de la declinación y priorizar los estadios de vida que deberían constituir el foco de atención de los esfuerzos de investigación y manejo. Estudios experimentales futuros de perturbaciones en uno o más estadios de la bistoria de vida deberán intentar ligar la magnitud de la perturbación medida con la magnitud de la respuesta general esperada a nivel poblacional dada la bistoria general de vida y las dinámicas poblacionales de la especie. Finalmente, los actuales esfuerzos de investigación, inventario y monitoreo deberán ser complementados con estudios demográficos de tal manera que los estudios cuantitativos puedan ser aplicados a un rango más amplio de especies y grupos de bistoria de vida.

$\ddagger$ Address correspondence to B.A. Maxell; email natbist@selway.umt.edu

Paper submitted October 10, 2000; revised manuscript accepted July 11, 2001.

728

Conservation Biology, Pages 728-734

Volume 16, No. 3, June 2002 


\section{Introduction}

Worldwide declines and losses of amphibian populations in a variety of human-disturbed and seemingly pristine habitats have increasingly become a concern to biologists, government agencies, and the general public (e.g., Stebbins \& Cohen 1995; Alford \& Richards 2000; Houlahan et al. 2000). Most research on amphibian declines has focused either on inventory and monitoring programs designed to identify the magnitude and geographic extent of declines or on experimental studies designed to identify mechanisms that affect specific lifehistory stages (e.g., Stebbins \& Cohen 1995; Blaustein et al. 1998; Kiesecker \& Blaustein 1998). Although both of these approaches are important-and necessary for detecting declines and identifying their potential causesby themselves they are not sufficient for determining actual causes of observed declines or predicting which perturbations in vital rates are most likely to cause future declines. For example, red-legged frogs (Rana aurora) have reportedly undergone declines throughout their range, and a well-designed experiment has shown that simultaneous exposure to introduced smallmouth bass (Micropterus dolomieui) and bullfrog (Rana catesbeiana) tadpoles reduces larval survival by $46 \%$ (Stebbins \& Cohen 1995; Kiesecker \& Blaustein 1998). What is missing is a consideration of the magnitude of the reduction in overall population growth rate $(\lambda)$ expected to result from the observed magnitude of the reduction in larval survival, given the general life history and population dynamics of the species. To identify whether purported mechanisms of decline are actually capable of causing declines and to ensure that management efforts are focused on the most likely causes of decline, a quantitative link needs to be made between observed reductions in vital rates and overall population-level effects.

Given the widespread application of population models to conservation issues (e.g., Burgman et al. 1993; Caswell 2000a), it is surprising that quantitative models have not been more widely applied to the problem of amphibian declines (for an exception, see Halley et al. 1996). Quantitative models of amphibian population dynamics can provide a critical link between inventory and monitoring programs and experimental studies by placing perturbations measured for different vital rates in the context of the population's overall $\lambda$. This link is essential, because equivalent changes in different vital rates can have different effects on $\lambda$ (Cole 1954; Caswell $2000 a$ ). Unfortunately, detailed demographic data is lacking for virtually all amphibian species. However, limited demographic information can still be used with generalized quantitative models, such as sensitivity analysis, to provide novel insights into life history and demography so that research and management efforts can be prioritized (Heppell et al. 2000a).
We demonstrate the application of two types of ecological sensitivity analysis to the problem of amphibian declines for red-legged frogs (Rana aurora), common frogs ( $R$. temporaria), and western toads (Bufo boreas). We chose these species as examples because they have undergone local or regional population declines (Cooke 1972; Stebbins \& Cohen 1995) and their vital rates have been relatively well documented.

\section{Methods}

For each species, we constructed female-based, postbirth pulse Lefkovitch matrices (Burgman et al. 1993; Caswell 2000a) with annual projection intervals representing a population with a life history consisting of three stages: prejuvenile (embryo, larva, and overwintering metamorph), juvenile, and reproductive adult. The matrix for this life history is

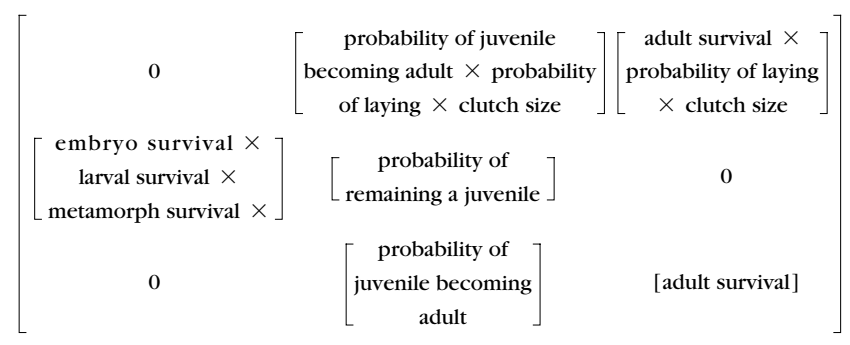

Vital-rate data used to parameterize the Lefkovitch matrices were obtained from the scientific literature (Table 1; for derivations of vital rates and matrix elements see Appendix at http://www.forestry.umt.edu/ amphib_sensitivity.pdf ). Because vital-rate estimates were not available for certain life-history stages of the three species we examined, data from congeneric species were used in some cases. Also, standard deviations (SD) associated with vital rates usually had to be inferred from observed ranges (maximum and minimum reported values). In addition, the available data did not allow us to distinguish between temporal, spatial, and sampling variation, all of which ideally should be separated in sensitivity analyses (Gould \& Nichols 1998; Mills \& Lindberg 2002).

We used elasticity analysis (Caswell 2000a; de Kroon et al. 2000) to quantify the proportional change in $\lambda$ that would result from an infinitesimal proportional change in individual vital rates based only on information on mean vital rates (Table 1). In addition, we used life-stage simulation analysis (LSA) to estimate the amount of variation in $\lambda$ explained by variation in each vital rate (Wisdom et al. 2000; Mills \& Lindberg 2002). For LSA, we calculated $\lambda$ at stable age distribution for 2000 replicate matrices generated by independently selecting clutchsize values from log-normal distributions and all other vital rates from $\beta$-distributions that represented the degree 
Table 1. Demographic vital rates and transition probabilities for Bufo boreas, Rana aurora, and Rana temporaria used in Lefkovitch matrix models. ${ }^{a}$

\begin{tabular}{|c|c|c|c|c|c|c|}
\hline Embryo survival & 0.78 & 0.36 & 0.92 & 0.05 & 0.92 & 0.05 \\
\hline Metamorph survival & 0.08 & 0.06 & 0.55 & 0.05 & 0.34 & 0.11 \\
\hline Juvenile survival $^{c}$ & 0.26 & 0.04 & 0.36 & 0.09 & 0.33 & 0.05 \\
\hline Juvenile to juvenile $^{d}$ & 0.26 & 0.04 & 0.26 & 0.04 & 0.25 & 0.03 \\
\hline Probability of laying & 0.50 & 0.25 & 1.00 & - & 1.00 & - \\
\hline Clutch size & 3532 & 856 & 303 & 95 & 650 & 133 \\
\hline Age at sexual maturity (years) & $4-7$ & - & 3 & - & 3 & - \\
\hline
\end{tabular}

${ }^{a}$ For derivations of vital rates and matrix elements see Appendix at bttp://www.forestry.umt.edu/amphib_sensitivity.pdf.

${ }^{b}$ Vital rates and transition probabilities are for females only and, with the exception of embryo, larval, and metamorph survival, which together encompass the first year of life, all are annual.

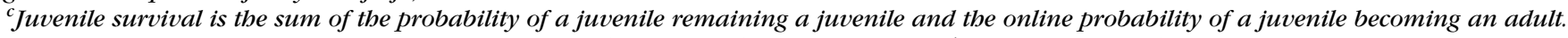
Due to uncertainty in the age of sexual maturity, this does not hold exactly true for B. boreas (see Appendix).

${ }^{d}$ Probability of a juvenile remaining a juvenile.

${ }^{e}$ Probability of a juvenile becoming an adult.

of variation reported for each vital rate (Table 1). Coefficients of determination $\left(r^{2}\right)$ were then calculated from regressions of asymptotic $\lambda$ on each individual vital rate for all 2000 simulations. Although elasticity and $r^{2}$ are calculated by very different approaches, they are related. Specifically, when $\lambda$ is a linear function of vital rates, $r^{2}$ is approximated by the product of elasticity squared and the proportional variance of a vital rate when vital rates vary independently (Wisdom \& Mills 1997; Caswell 2000b).

Because of uncertainty associated with some of the vital rates used (see Appendix at http://www.forestry. umt.edu/amphib_sensitivity.pdf), we assessed the robustness of our results to potential inaccuracies in vitalrate means and variances (Mills et al. 1999). We repeated elasticity analysis with matrices containing mean values one SD greater and smaller than the original values, with all other vital rates held at baseline levels. For LSA we repeated our analysis with baseline mean values and a SD that was 0.5 and 1.5 times the original SD of each individual vital rate, with the variance of all other vital rates held at baseline values. The robustness of our findings for both types of sensitivity analysis was assessed by the degree to which the rank of each vital rate at high and low mean (for elasticity analysis) and high and low SD (for LSA) differed from its rank at baseline mean and SD.

\section{Results}

Changes in vital rates did not have equal effects on $\lambda$. Although the elasticity of $\lambda$ did not differ greatly between individual vital rates, it was highest for adult and/or juvenile survival for all three species, indicating that the greatest proportional change in $\lambda$ would be expected to result from a change in these vital rates (Fig. 1a). Differences are exacerbated if we combine the individual-component vital rates that are likely to be simultaneously affected by the same types of perturbations. For example, when elasticities of vital rates associated with all pre- and post-metamorphic life-history stages are summed, the cumulative elasticities of the post-metamorphic vital rates far outweigh those of the pre-metamorphic vital rates (Fig. 1a $\& 1 b)$. This means that simultaneous equivalent reductions of all post-metamorphic vital rates will result in a much greater reduction in $\lambda$ than simultaneous reductions of all pre-metamorphic vital rates. With the exception of $B$. boreas, the ranking of vital rates by elasticity values was robust in that it did not deviate from the patterns observed previously for any of the species when mean vital rates were varied by plus or minus $1 \mathrm{SD}$ (data not shown). For B. boreas several vital rates that were tied in terms of having the second highest elasticity value (Fig. 1a) became the highest ranked when their means were individually varied to $1 \mathrm{SD}$ above their baseline value.

In general, for LSA, the most variable vital rates (Table 1) had the highest coefficients of determination $\left(r^{2}\right)$ and therefore best explained overall variation in $\lambda$ (Fig. 1c). As a result, the LSA results varied more among species: several vital rates had similar $r^{2}$ values in $B$. boreas, whereas juvenile and larval survival had by far the highest values in $R$. aurora and $R$. temporaria, respectively. When $r^{2}$ values associated with all pre- and post-metamorphic lifehistory stages were summed, the cumulative $r^{2}$ of the postmetamorphic vital rates were greater in $B$. boreas and $R$. aurora, whereas the cumulative $r^{2}$ of the pre-metamorphic vital rates were greater in $R$. temporaria (Fig. 1d). The relative rankings of $r^{2}$ values for each vital rate did not change by more than one or two places in $R$. aurora 

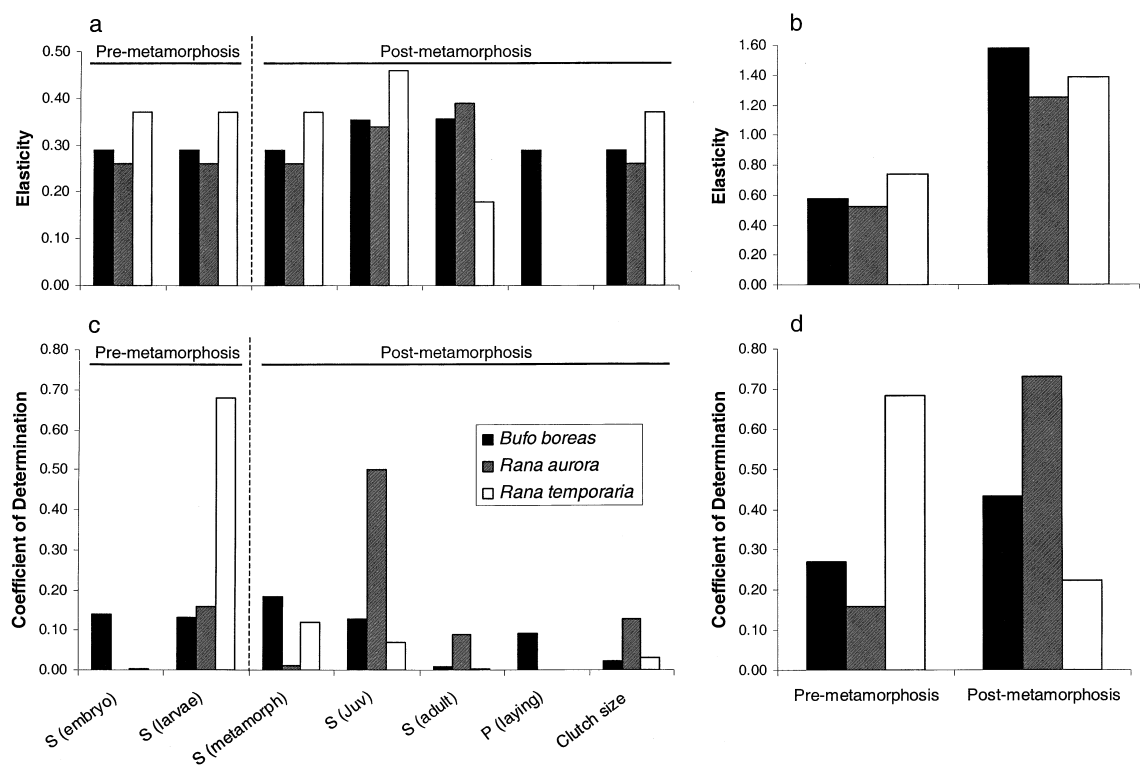

Figure 1. The relative effect of individual vital rates $(a \& c)$ and all pre- and post-metamorphic vital rates ( $b \& d)$ on the overall population growth rate $(\lambda)$ of Bufo boreas, Rana aurora, and Rana temporaria, as measured by elasticities ( $a \& b$ ) and coefficients of determination $\left(\mathrm{r}^{2}\right)(c \& d)$. The $\mathrm{S}$ is the survival probability of the given stage, and $\mathrm{P}$ (laying) is the probability of laying. Pre-metamorphic vital rates are $\mathrm{S}(e m b r y o)$ and $\mathrm{S}$ (larvae), and post-metamorphic vital rates are $\mathrm{S}$ (metamorph), $\mathrm{S}$ (juvenile), $\mathrm{S}$ (adult), $\mathrm{P}$ (laying), and clutch size. Elasticities and $\mathrm{r}^{2}$ values for pre- and post-metamorphic vital rates measure the relative effect of simultaneous reductions in preand post-metamorphic rates on $\lambda$. and $R$. temporaria when the SD was varied to high and low levels for each vital rate (Table 2). However, the ranking of $r^{2}$ values for $B$. boreas vital rates was less robust as the ranks of some of the highest-ranked rates at baseline SD changed by up to four places when SD was increased or decreased.

\section{Discussion}

A key result of our analysis is that the elasticity of $\lambda$ was highest for juvenile or adult survival in all three species (Fig. 1a). This indicates that, for the general life history and demography of these species, a given reduction in mean juvenile or adult survival is more likely to lead to population declines than the same magnitude of reduction in other vital rates. Moreover, if juvenile and adult survival are reduced simultaneously, the cumulative reduction in $\lambda$ will be even greater. A simultaneous reduction in juvenile and adult survival is a realistic scenario, because the natural histories of juveniles and adults of these species are similar.

To demonstrate the cumulative importance of juvenile and adult survival, we considered the impact on $B$. boreas $\lambda$ from a hypothetical $15 \%$ reduction in these two vital rates. We compared this to the $49 \%$ reduction in embryo survival reported in an experimental study in Oregon as a result of the interaction of the fungus Saprolegnia ferax and ambient UV radiation (Kiesecker \& Blaustein 1995). With the baseline vital rates and population matrix used for our analysis, the $15 \%$ reduction in juvenile and adult survival results in an approximately $19 \%$ decline in $\lambda$. In comparison, the $49 \%$ reduction in embryo survival re- sults in a $16 \%$ decline in $\lambda$. This shows that when $\lambda$ has a high elasticity to one or more vital rates-juvenile and adult survival in this case-relatively large effects on $\lambda$ can result from relatively small perturbations of these rates. However, the example highlights the fact that equivalent reductions in $\lambda$ can also be caused by a relatively large reduction in a rate with a low elasticity, in this case embryo survival. In addition, smaller but simultaneous reductions of multiple vital rates with low elasticities can result in large reductions in $\lambda$.

The finding that the elasticity of $\lambda$ was highest for postmetamorphic vital rates in all three species is consistent with the observation that overall life-history patterns rather than specific vital-rate values determine elasticity rankings in many species (Heppell et al. 2000b). This indicates that research and management efforts designed to document and prevent perturbations of post-metamorphic vital rates should clearly be a priority for these species and others with similar life histories. This is an important insight because, to date, experimental studies of putative mechanisms of decline for these and other north-temperate species in the families Bufonidae and Ranidae have focused on embryo and larval survival (e.g., Corn \& Vertucci 1992; Kiesecker \& Blaustein 1995, 1998; Blaustein et al. 1998). Probably driven in part by logistic considerations, this "bias" may be confounding the current view of which mechanisms of decline represent the greatest threats to the persistence of amphibian populations.

Life-stage simulation analysis provided additional insights into the population dynamics of these species. In general, LSA identified the most variable vital rates as best explaining overall variation in $\lambda$ : juvenile-adult transition of $R$. aurora, larval survival of $R$. temporaria, and 
Table 2. Ranks of coefficients of determination $\left(r^{2}\right)$ for vital rates in life-stage simulation analysis ( LSA) of Bufo boreas, Rana aurora, and Rana temporaria, with standard deviations ( SD) from Table 1 (baseline) and 1.5 (high) and 0.5 (low) times the baseline SD, with all other vital rate SDs held at baseline levels. ${ }^{a}$

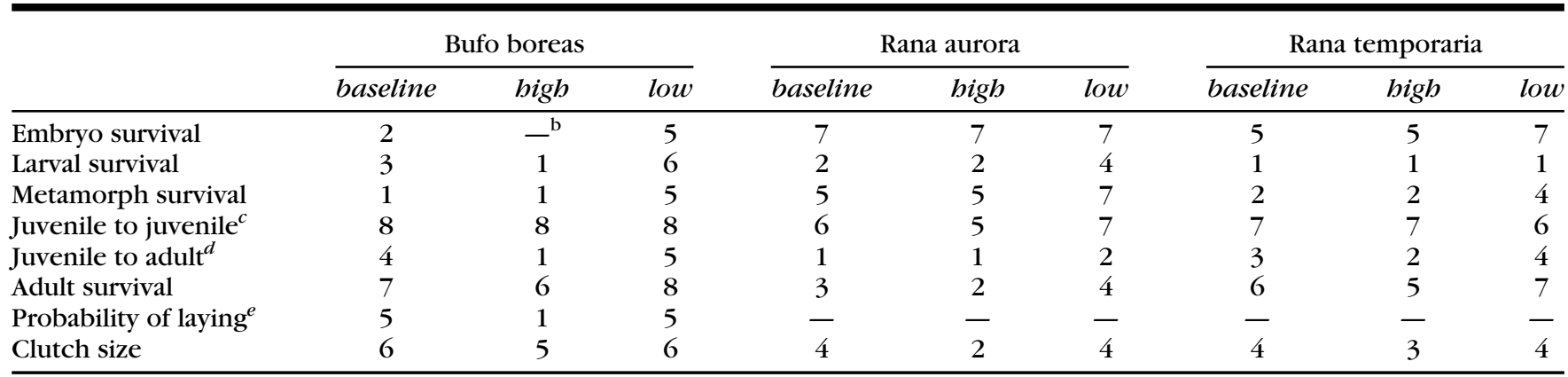

${ }^{a}$ Robustness comparisons are in rows, not columns. For example, because the rank of larval survival for $\mathrm{B}$. boreas changes from the third most important vital rate at baseline SD to the most important with a bigh SD and then to the sixth most important with a low SD, the baseline rank is less robust than it is for $\mathrm{R}$. temporaria, whose rank remains at 1 for baseline, high, and low $S D$.

${ }^{b}$ The LSA could not be conducted for $\mathrm{B}$. boreas embryo survival with a high SD because of the already exceptionally high level of variation reported for this vital rate.

${ }^{c}$ Probability of a juvenile remaining a juvenile.

${ }^{d}$ Probability of a juvenile becoming an adult.

${ }^{e}$ Probability of laying is not explicitly shown as a vital-rate component for R. aurora or R. temporaria because probability of laying was assumed to be 1.0 for these species and therefore is implicitly included in clutch size.

several variable vital rates for $B$. boreas (Table 1 ; Fig. 1c). These vital rates have a strong effect on the population dynamics of these species in part because they occasionally take on extremely high and low values. Variability in these rates may therefore be an important cause of natural variation in $\lambda$ for these species.

The fact that the rankings of $r^{2}$ values for each vital rate remained similar to the baseline patterns for $R$. aurora and $R$. temporaria when the SD of each rate was changed to its high and low level (Table 2) indicates that our findings are fairly robust to the estimates of vital-rate variation used for these species. This is important given the limited demographic data that were available with which to parameterize our matrix models. The fact that the ranks of $r^{2}$ values for $B$. boreas vital rates were not robust when the SD of individual rates was increased and decreased indicates that uncertainties associated with vital-rate estimates may currently hinder the application of sensitivity analyses that incorporate variation in guiding appropriate management decisions for this species. This may, in part, be a result of the variability in the life history and demography of the species but highlights the need for studies documenting the mean and spatial and temporal variance of the vital rates of $B$. boreas.

The identification of vital rates that tend to drive natural fluctuations in $\lambda$ through the use of LSA has two implications for the problem of declining amphibian populations. First, these vital rates are likely to play a key role in the persistence of populations because exceptionally high or low values of these rates may be the primary causes of population increases or decreases, respectively. Second, the high variability of these rates suggests that they are promising targets of management strategies for population recovery. If the low end of the range of variation in these rates can be eliminated, the positive response in $\lambda$ should be strong. Recovery of Rana temporaria populations in some areas may be an example of this. Past reports of declines in this species refer mainly to agricultural areas and stand in contrast to local population increases attributed to the widespread creation of artificial ponds (Cooke 1972). It is possible that artificial ponds are less prone to drying out and could have eliminated the lower end of the range of larval survival of $R$. temporaria. Based on our analysis for this species such a change would likely result in increases in $\lambda$ (Fig. 1c \& 1d) and could therefore be responsible for population recoveries in these areas.

\section{Conservation Recommendations}

Our analyses indicate that because all vital rates do not contribute equally to $\lambda$, experimental studies of purported mechanisms of amphibian decline should try to place the magnitude of the perturbation they have measured for one or more vital rates in the context of the overall expected response in $\lambda$. In addition, we suggest that sensitivity analysis should be used to develop and test hypotheses for putative causes of amphibian declines. Elasticity analysis is particularly useful for identifying vital rates that, when reduced by equal amounts, are expected to result in the largest decreases in $\lambda$. Life-stage simulation analysis (LSA) is particularly useful for identifying rates that, due to their high variability, exhibit a strong effect on $\lambda$ at certain times or localities. Monitoring these rates closely should therefore greatly improve our understanding of the spatial and temporal dynamics of amphibian populations. In addition, we believe that these vital rates could be useful in management efforts to aid population recovery. Be- 
cause they owe their high $r^{2}$ values in part to their high variability, increasing these rates by eliminating their lower range of variation should be an effective way to increase $\lambda$.

Our analyses have implications for the direction of regional and national research programs on amphibian declines. For example, the U.S. Department of the Interior's Amphibian Research and Monitoring Initiative is designed to collect information at several hierarchical levels, from extensive surveys to intensive studies of single species (Hall \& Langtimm 2001). Within this type of research framework, we suggest that at least some focal studies be initiated to collect long term demographic information for individual species within each of the geographic regions where a species' life history and population dynamics are likely to be similar (e.g., high- and lowelevation populations in major latitudinal and climatological zones). Ideally, data on the correlation structure of vital rates, density-dependent responses of vital rates, and the effects of emigration and immigration on the population dynamics of these focal populations would all be gathered. This information could then be used in quantitative models to place the results of experimental studies of suspected mechanisms of decline in a populationlevel context or the context of the results of regional monitoring programs. Ideally, this would allow management efforts to be proactively focused on mechanisms that are most likely to result in population declines in order to prevent declines from occurring in the first place.

Gathering detailed demographic data for many species in north-temperate latitudes is an achievable goal given the low species diversity (Duellman 1999) and relative wealth of many nations at these latitudes. However, in areas with limited research funding and high species diversity such as the American, African, and Asian tropics, we advocate grouping species by general life history and/or taxonomic group and gathering demographic information for a few species representative of that group. With this strategy, species for which demographic data exist could then be used as surrogates to provide insights into the life histories, population dynamics, and suspected mechanisms of decline of other species (Heppell et al. 2000a; 2000b). Given the urgency of the "amphibian crisis", it is critical that limited resources be used efficiently and effectively. Application of sensitivity analysis and other quantitative models can help prioritize research and management efforts and thereby improve the prospects for conserving the world's amphibian diversity.

\section{Acknowledgments}

We thank two anonymous reviewers, R. C. Beattie, T. J. C. Beebee, C. Carey, J. J. Citta, A. S. Cooke, P. S. Corn, J. Elmberg, S. S. Heppel, S. T. Hoekman, D. G. Hokit, J. Kiesecker, L. Licht, M. Lindberg, and H. M. Wilbur for reviewing vital-rate information on the species used in the analyses and for providing a number of insightful comments on various drafts of this manuscript. Partial support for this work came from University of Montana research and teaching assistantships to R.B. and B.A.M., a National Science Foundation (NSF) Graduate Research Fellowship to W.C.F., and grants to L.S.M. from the NSF (DEB-9870654) and U.S. Department of Agriculture (NRICGP 97-35101-4355).

\section{Literature Cited}

Alford, R. A., and S. J. Richards. 2000. Global amphibian declines: a problem in applied ecology. Annual Review of Ecology and Systematics 31:133-165.

Blaustein, A. R., J. M. Kiesecker, D. P. Chivers, D. G. Hokit, A. Marco, L. K. Belden, and A. Hatch. 1998. Effects of ultraviolet radiation on amphibians: field experiments. American Zoologist 38:779-812.

Burgman, M. A., S. Ferson, and H. R. Akçakaya. 1993. Risk assessment in conservation biology. Chapmann and Hall, New York.

Caswell, H. 2000a. Matrix population models: construction, analysis, and interpretation. 2nd edition. Sinauer Associates, Sunderland, Massachusetts.

Caswell, H. 2000b. Prospective and retrospective perturbation analyses: their roles in conservation biology. Ecology 81:619-627.

Cole, L. C. 1954. The population consequences of life history phenomena. Quarterly Review of Biology 29:103-137.

Cooke, A. S. 1972. Indications of recent changes in status in the British Isles of the frog (Rana temporaria) and the toad (Bufo bufo). Journal of Zoology, London 167:161-178.

Corn, P. S., and F. A. Vertucci. 1992. Descriptive risk assessment of the effects of acid deposition on Rocky Mountain amphibians. Journal of Herpetology 26:361-369.

de Kroon, H., J. van Groenendael, and J. Ehrlen. 2000. Elasticities: a review of methods and model limitations. Ecology 81:607-618.

Duellman, W. E. 1999. Patterns of the distribution of amphibians: a global perspective. Johns Hopkins University Press, Baltimore, Maryland.

Gould, W. R., and J. D. Nichols. 1998. Estimation of temporal variability of survival in animal populations. Ecology 79:2531-2538.

Hall, R. J., and C. A. Langtimm. 2001. The U.S. National Amphibian Research and Monitoring Initiative and the role of protected areas. The George Wright FORUM 18(2):14-25.

Halley, J. M., R. S. Oldham, and J. W. Arntzen. 1996. Predicting the persistence of amphibian populations with the help of a spatial model. Journal of Applied Ecology 33:455-470.

Heppell, S. S., H. Caswell, and L. B. Crowder. 2000a. Life histories and elasticity patterns: perturbation analysis for species with minimal demographic data. Ecology 81:654-665.

Heppell, S. S., C. Pfister, and H. de Kroon. 2000b. Elasticity analysis in population biology: methods and applications. Ecology 81:605-606.

Houlahan, J. E., C. S. Findlay, B. R. Schmidt, A. H. Meyer, and S. L. Kuzmin. 2000. Quantitative evidence for global amphibian population declines. Nature 404:752-755.

Kiesecker, J. M., and A. R. Blaustein. 1995. Synergism between UV-B radiation and a pathogen magnifies amphibian embryo mortality in nature. Proceedings of the National Academy of Sciences of the United States of America 92:11049-11052.

Kiesecker, J. M., and A. R. Blaustein. 1998. Effects of introduced bullfrogs and smallmouth bass on microhabitat use, growth, and survival of native red-legged frogs (Rana aurora). Conservation Biology 12:776-787.

Mills, L. S., and M. Lindberg. 2002. Sensitivity analysis to evaluate the consequences of conservation actions. Pages 338-366 in S. R. Beissinger and D. R. McCullough, editors. Population viability analysis. University of Chicago Press, Chicago.

Mills, L. S., D. F. Doak, and M. J. Wisdom. 1999. Reliability of conserva- 
tion actions based on elasticity analysis of matrix models. Conservation Biology 13:815-829.

Stebbins, R. C., and N. W. Cohen. 1995. A natural history of amphibians. Princeton University Press, Princeton, New Jersey.

Wisdom, M. J., and L. S. Mills. 1997. Using sensitivity analysis to guide population recovery: prairie-chickens as an example. Journal of Wildlife Management 61:302-312.

Wisdom, M. J., L. S. Mills, and D. F. Doak. 2000. Life stage simulation analysis: estimating vital-rate effects on population growth for conservation. Ecology 81:628-641.

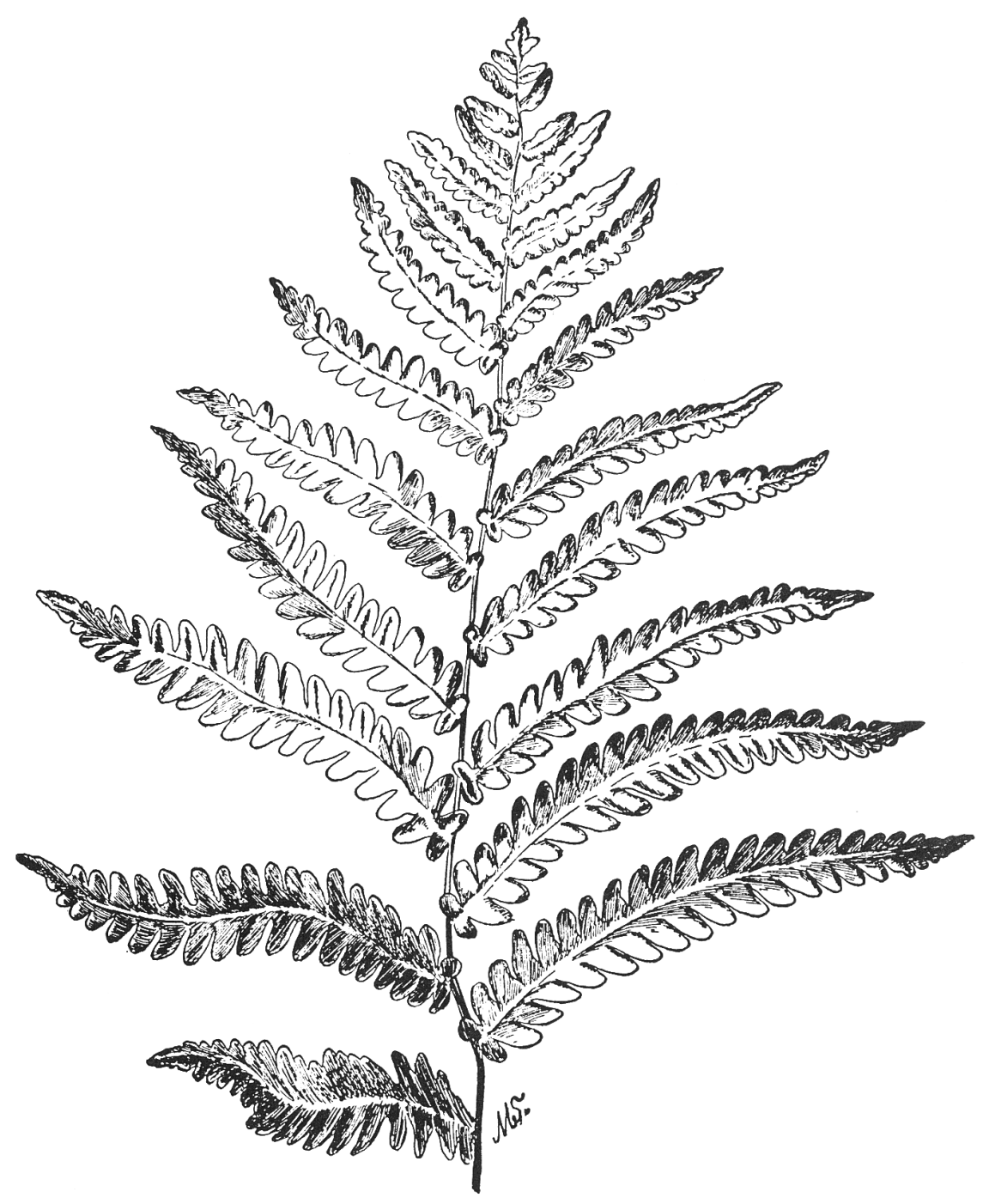




\title{
What is Missing In Amphibian Decline Research: Insights From Ecological Sensitivity Analysis
}

\begin{abstract}
Appendix

\section{Derivation of Vital Rates and Matrix Elements Used in Sensitivity Analyses}

For each species, we attempted to gather demographic vital rate information reported in the scientific literature within a single bioregion in order to avoid confounding variation in life history and demography that is often evident across a species geographic range (Turner 1962; Pettus \& Angleton 1967; Berven 1982; Berven \& Gill 1983; Hemelaar 1988).

Bioregions of focus for each species were subalpine and alpine habitats in the western United States for Bufo boreas, maritime habitats in the Pacific Northwest of North America for Rana aurora, and lowland habitats in the British Isles for Rana temporaria. Unfortunately, not all vital rate information was available for each species within these bioregions and use of vital rate information from conspecifics outside the bioregion of focus or congeners within or outside the region of focus was sometimes necessary. Species experts reviewed all vital rates in order to ensure that they were representative of the species in the bioregion of focus.

Derivations of the means and standard deviations (SD) of all component vital rates and matrix elements are shown below for each species. All vital rates shown are for females only, so vital rates specific to females were used if available and all clutch sizes are divided by two (assuming a 1:1 sex ratio) in order to represent female embryos only. Variances associated with clutch sizes were divided by four (two squared) to yield the variance associated with just the female embryos (Seber 1982). When only a range was available for a particular vital rate the midpoint of the range was used as the mean and one quarter of the range was used as the $\mathrm{SD}$, assuming that the range approximates a 95\% confidence interval with two SDs above and below the mean. If the range was not symmetrical around the mean
\end{abstract}


value in the range the SD was calculated as one half the difference between the mean value and the range boundary that differed to the greatest extent from the mean. When multiple studies were used to derive a vital rate a mean of the means and SDs reported in the different studies was used as the mean and SD. If variances were not reported for individual studies then one quarter of the range between the high and low reported means was used as the SD. The transition formula used for the probability of a juvenile staying a juvenile is $P 1=\left(\left(1-p_{i}{ }^{\text {di- }}\right.\right.$ $\left.\left.{ }^{1}\right) * \mathrm{pi}\right) /\left(1-\mathrm{p}_{\mathrm{i}}{ }^{\mathrm{di}}\right)$ (Crouse et al. 1987). The transition formula used for the probability of a juvenile becoming an adult is $\mathrm{G} 2=\left(\mathrm{p}_{\mathrm{i}}{ }^{\mathrm{di}} *\left(1-\mathrm{p}_{\mathrm{i}}\right)\right) /\left(1-\mathrm{p}_{\mathrm{i}}{ }^{\mathrm{di}}\right)($ Crouse et al. 1987). In these formulas, $p_{i}$ is the annual survival probability of a juvenile and $d_{i}$ is the number of years spent as a juvenile. Mean values for these two matrix elements were calculated as the product of the mean or most likely value of the component vital rates for that element. The SD of these two matrix elements was calculated as either one half the difference between the mean element value and the range boundary (calculated by either multiplying all high or all low range component values together) that differed to the greatest extent from the mean value or as one quarter of the range between the product of all high and all low component values.

\section{Western Toad (Bufo boreas)}

\section{Embryo Survival}

A mean of 0.784 is the product of the proportion of egg strings that did not suffer complete mortality (0.857) and the survival rate of these embryos (0.915) for the Lost Lake, Colorado population in 1994 (Corn 1998; Carey et al. 2002). A SD of 0.364 was calculated from the embryo survival values reported for embryos exposed to ambient levels of UV-B radiation $(0.76,0.92,0.85,0.83,0.97,1.0,0.96,0.88,1.0,0.99)$ for the proportion of the clutches that survived $(30 / 35=0.857)$ and the proportion of the clutches that suffered complete mortality $(5 / 35=0.143)($ Corn 1998) . 


\section{$\underline{\text { Larval Survival }}$}

A mean of 0.470 is based on the midpoint between a low value of 0.0 reported for several populations in Colorado as a result of complete predation or failure to metamorphose before winter (Carey et al. 2002) and a high value of 0.94 reported for B. boreas in the lab (Worrest \& Kimeldorf 1975). SD of 0.235 is based on one quarter of the difference between the high and low values above.

\section{Overwintering Metamorph Survival}

No quantitative estimates of overwintering metamorph survival are available for $B$. boreas and the only known report for a bufonid is 0.32 for overwintering $B$. woodhousii metamorphs in Connecticut (Clarke 1977); a value that would only feasibly represent a "boom" recruitment year for $B$. boreas. A number of studies report almost complete metamorph mortality for $B$. boreas as a result of natural factors including predation and freezing (Carey et al. 2002; Olson 1992; Sornborger 1979; Jones 1998). However, there are also reports of rare "boom" recruitment years with large numbers of overwintering metamorphs observed at only 1 of 19 breeding aggregations over 6 years in the Cascade Mountains of Oregon (Olson 1992). Therefore, the mean of 0.081 is based on the value that yields an overall mean survival rate for embryos, larvae, and metamorphs of $0.03(0.784 \times 0.470 \times 0.081)$ (Olson 1992; Sornborger 1979; Jones 1998). The SD of 0.058 is based on one "boom" recruitment event with an overwintering survival of 0.32 and eighteen "normal" recruitment events with an overwintering survival of 0.069 (yielding an overall mean of 0.081 ) as a hypothetical approximation of the levels of metamorph survival and the boom/bust type of recruitment pattern reported above.

$\underline{\text { Juvenile Survival }}$

No quantitative estimates of juvenile survival are available for $B$. boreas. However, estimates for B. woodhousii in Connecticut were 0.18 (Clarke 1977) and estimates for $B$. 
canorus in the Sierra Nevada Mountains in California were 0.348 (Kagarise Sherman 1980). Therefore, the mean of 0.264 is based on the midpoint of the range between the absolute low and high estimates for these species $(0.18-0.348)$. The SD of 0.042 is based on one quarter of the difference between the high and low range boundaries above.

\section{Probability of a Juvenile Remaining a Juvenile (P1)}

A mean of 0.261 is based on the midpoint of the value of the P1 matrix element $(0.175)$ resulting from the low boundary of juvenile survival (0.18) and female sexual maturity at 4 years post metamorphosis (Olson 1992) (i.e. 3 years as a juvenile) and the value of the P1 matrix element $(0.347)$ resulting from the high boundary of juvenile survival $(0.348)$ and female sexual maturity at 7 years post metamorphosis (Carey et al. 2002) (i.e. 6 years as a juvenile) using the P1 formula shown above (Crouse et al. 1987). A SD of 0.043 is based on one quarter of the difference between the high and low P1 matrix elements above.

Probability of a Juvenile Becoming an Adult (G2)

A mean of 0.014 is based on the midpoint of the value of the G2 matrix element $(0.000028)$ resulting from the low boundary of juvenile survival (0.18) and female sexual maturity at 7 years post metamorphosis (Carey et al. 2002) (i.e. 6 years as a juvenile) and the value of the G2 matrix element (0.029) resulting from the high boundary of juvenile survival (0.348) and female sexual maturity at 4 years post metamorphosis (Olson 1992) (i.e. 3 years as a juvenile) using the G2 formula shown above (Crouse et al. 1987). A SD of 0.007 is based on one quarter of the difference between the high and low G2 matrix elements above.

\section{$\underline{\text { Adult Survival }}$}

A mean value of $0.78(95 \%$ C.I. $=0.65-0.90)$ is based on mean annual survival estimates for males (too few females returned during the study to estimate female survival) in a stable population over 5 years in Rocky Mountain National Park, Colorado (P. S. Corn, Aldo Leopold Institute, personal communication). A SD of 0.065 is based on one half of the 
difference between the mean and the $95 \%$ C.I. boundary that differed the most from the mean (0.65).

\section{Probability of Laying}

A mean of 0.50 is based on the most likely value from a report of $19 \%$ of returning females reproducing annually, 55\% reproducing biennially, 22\% reproducing triennially, and $7 \%$ reproducing quadrennially in the Cascade Mountains of Oregon (Olson 1992). A SD of 0.25 is based on one half of the difference between the most likely value and the range boundary that differed the most from the mean (1.0).

\section{Clutch Size}

A mean of 3,532 female embryos is based on one half of the mean of full clutches reported for three locations in Colorado (West Elk Mountains: mean $=5,897, \mathrm{SD}=1,663, \mathrm{~N}=21$; Rocky Mountain National Park: mean $=8,155, \mathrm{SD}=1,908, \mathrm{~N}=4$; Urad Valley: mean $=$ $7,440, \mathrm{SD}=1,568, \mathrm{~N}=13$ ) (Carey et al. 2002) and one location in southern California at Mount San Jacinto State Park $($ mean $=6,764, S D=1,694, N=4)$ (Sornborger 1979). A SD of 856 is based on the average of the four variances reported above, divided by four to represent variation for female embryos only.

\section{Red-legged Frog (Rana aurora)}

\section{Embryo Survival}

A mean of 0.920 is based on the mean reported for a population in the Lower Fraser Valley of British Columbia (Licht 1974). A SD of 0.046 is based on the SD reported for the study above.

\section{$\underline{\text { Larval Survival }}$}

A mean of 0.030 is based on the mean of larval survival rates reported for adjacent pond (0.006) and stream (0.053) sites in the Lower Fraser Valley of British Columbia (Licht 1974) 
A SD of 0.012 is based on one quarter of the difference between the values reported for the two sites above.

\section{Overwintering Metamorph Survival}

A mean of 0.549 is based on the mean of equivalent 8-month survival probabilities calculated from a 12-month survival probability reported for R. aurora in the Lower Fraser Valley of British Columbia (0.52) (Licht 1974) and from a 6-month survival probability reported for $R$. cascadae near Sisters, Oregon (0.55) (Briggs \& Storm 1970), yielding 0.647 and 0.451, respectively. A SD of 0.049 is based on one quarter of the difference between the two equivalent 8-month survival probabilities above.

\section{$\underline{\text { Juvenile Survival }}$}

No quantitative estimates of juvenile survival are available for $R$. aurora. Therefore, the mean of 0.355 is based on the mean estimate for R. cascadae near Sisters, Oregon (Briggs \& Storm 1970). The SD of 0.093 is based on one quarter of the difference between the high (0.79) and low (0.42) estimates of juvenile survival for R. luteiventris in Yellowstone National Park, Wyoming (Turner 1960).

\section{Probability of a Juvenile Remaining a Juvenile (P1)}

A mean of 0.262 is based on a mean juvenile survival of 0.355 and female sexual maturity at 3 years post-metamorphosis (Licht 1974) (i.e. 2 years as a juvenile) using the P1 formula shown above (Crouse et al. 1987). A SD of 0.036 is based on one quarter the difference between the high P1 matrix element value (0.441) calculated using the high juvenile survival estimate of 0.79 and the low P1 matrix element value (0.296) calculated using the low survival estimate of 0.42 .

$\underline{\text { Probability of a Juvenile Becoming an Adult (G2) }}$

A mean of 0.093 is based on a mean juvenile survival of 0.355 and female sexual maturity at 3 years post-metamorphosis (Licht 1974) (i.e. 2 years as a juvenile) using the G2 formula 
shown above (Crouse et al. 1987). A SD of 0.056 is based on one quarter the difference between the high G2 matrix element value (0.349) calculated using the high juvenile survival estimate of 0.79 and the low G2 matrix element value (0.124) calculated using the low survival estimate of 0.42 .

\section{$\underline{\text { Adult Survival }}$}

A mean value of 0.686 is based on the mean value reported for populations in the Lower Fraser Valley of British Columbia (Licht 1974). No estimates of variation have been reported for $R$. aurora. A SD of 0.133 is based on one quarter of the range (0.43-0.96) reported for $R$. luteiventris populations in Yellowstone National Park, Wyoming (Turner 1960).

\section{Probability of Laying}

A mean of 1.0 and a SD of 0.0 is based on evidence that all females breed annually (Licht 1974).

\section{$\underline{\text { Clutch Size }}$}

A mean of 303 female embryos is based on one half of the mean of full clutches reported for the Lower Fraser Valley (mean $=680, \mathrm{SD}=243$ (calculated as one half of the difference between the reported mean and lowest value)) (Licht 1974) and Marion Lake, British Columbia (mean 531, SD = 112, $\mathrm{N}=35$ ) (Calef 1973). A SD of 95 is based on the average of the two variances reported above, divided by four to represent variation for female embryos only.

\section{Common Frog (Rana temporaria)}

\section{Embryo Survival}

A mean of 0.921 is based on a weighted average from a study in southern England (Cooke 1985) where over a 13 year period $97.5 \%$ of the eggs were found to hatch normally and $2.5 \%$ 
showed unusually low hatch rates. Respective rates of 0.939 (range $0.839-0.986, \mathrm{~N}=11$ ) for normal hatch and 0.200 for low hatch $(\mathrm{N}=1)$ were determined under laboratory conditions by the same author (Cooke 1975). The SD of 0.05 is equivalent to the SD for normal hatch only (based on one half of the difference between the mean of 0.939 and the lower range boundary for normal hatches of 0.839). The fact that low hatches are not included in this SD is justified by the fact that they occur with a frequency of less than $5 \%$ and, therefore, fall outside of the $95 \%$ range covered by two SDs.

\section{$\underline{\text { Larval Survival }}$}

A mean of 0.061 is based on the average of two estimates $(0.025,0.062)$ reported from Denmark (Riis 1991) and low and high range estimates (0.0 and 0.155) reported for a population in Poland (Ryszkowski \& Truszkowski 1975). No associated estimates of variation were available so the SD of 0.047 is based on half the difference between the estimated mean and the high range estimate.

\section{Overwintering Metamorph Survival}

No quantitative estimates for either the mean or variance of overwintering metamorph survival are available for $R$. temporaria. Therefore, the mean of 0.336 is based on an equivalent 9-month survival probability calculated from the 8-month survival probability (mean $=0.379, \mathrm{SD}=0.120, \mathrm{~N}=7$ ) reported for metamorphosed $R$. sylvatica in Maryland (Berven 1990). The SD of 0.106 is based on the same CV as reported for the $R$. sylvatica study above.

\section{$\underline{\text { Juvenile Survival }}$}

No quantitative estimates for either the mean or variance of juvenile survival are available for R. temporaria. Therefore, the mean of 0.332 is based on the midpoint between the 12 -month equivalent of metamorph survival (0.233) and adult survival (0.430). The SD of 0.049 is based on one quarter of the difference between the above values. 


\section{Probability of a Juvenile Remaining a Juvenile (P1)}

A mean of 0.249 is based on a mean juvenile survival of 0.332 and female sexual maturity at 3 years post-metamorphosis (Gibbons \& McCarthy 1984) (i.e. 2 years as a juvenile) using the P1 formula shown above (Crouse et al. 1987). A SD of 0.028 is based on one quarter of the difference between the high P1 matrix element value (0.301) calculated using the high juvenile survival estimate of 0.430 and the low P1 matrix element value (0.189) calculated using the low survival estimate of 0.233 .

\section{Probability of a Juvenile Becoming an Adult (G2)}

A mean of 0.083 is based on a mean juvenile survival of 0.332 and female sexual maturity at 3 years post-metamorphosis (Gibbons \& McCarthy 1984) (i.e. 2 years as a juvenile) using the G2 formula shown above (Crouse et al. 1987). A SD of 0.021 is based on one quarter the difference between the high G2 matrix element value (0.129) calculated using the high juvenile survival estimate of 0.430 and the low G2 matrix element value (0.044) calculated using the low survival estimate of 0.233 .

\section{Adult Survival}

A mean value of 0.430 is based on the midpoint of estimates reported in southern Sweden (0.360) (Loman 1984) and western Ireland (0.500) (Gibbons \& McCarthy 1984). No estimates of variation have been reported for R. temporaria, so a SD of 0.035 is based on one quarter of the difference between the two values above.

\section{Probability of Laying}

A mean of 1.0 and a SD of 0.0 is based on evidence that all females breed annually (Miaud 1999). 


\section{Clutch Size}

A mean of 650 female embryos is based on one half of the mean of full clutches reported for four localities in England and Ireland, (Cambridgeshire: mean =1,329, SD = 180, N = 7 (Cooke 1975); English lowlands: mean =1,273, $\mathrm{N}=196$ (no measure of variation available) (Cummins 1986); Northern English lowlands: mean = 1,586, (no standard deviation available) (Beattie 1987); western Ireland: mean $=1008, \mathrm{SD}=331, \mathrm{~N}=274$ (Gibbons \& McCarthy 1986). A SD of 133 is based on the average variance of the two studies above that reported levels of variation, divided by four to represent variation for female embryos only.

\section{Literature Cited}

Beattie, R. C. 1987. The reproductive biology of common frog (Rana temporaria) populations from different altitudes in northern England. Journal of Zoology, London 211:387-398.

Berven, K. A. 1982. The genetic basis of altitudinal variation in the wood frog, Rana sylvatica. I. An experimental analysis of life history traits. Evolution 36:962-983.

Berven, K. A. 1990. Factors affecting population fluctuations in larval and adult stages of the wood frog (Rana sylvatica). Ecology 71:1599-1608.

Berven, K. A., and D. E. Gill. 1983. Interpreting geographic variation in life-history traits. American Zoologist 23:85-97.

Briggs, J. L., and R. M. Storm. 1970. Growth and population structure of the Cascade frog, Rana cascadae Slater. Herpetologica 26:283-300.

Calef, G. W. 1973. Natural mortality of tadpoles in a population of Rana aurora. Ecology 54:741-758.

Carey, C., P. S. Corn, L. J. Livo, M. Jones, C. Leoffler, and E. Muths. 2002. Environmental and life history factors that retard recovery in southern Rocky Mountain populations of 
boreal toads (Bufo boreas boreas). In press in M. J. Lannoo, editor. Status and conservation of United States amphibians. University of California Press, Berkeley, California.

Clarke, R. D. 1977. Postmetamorphic survivorship of Fowler's toad, Bufo woodhousei fowleri. Copeia 1977:594-597.

Cooke, A. S. 1975. Spawn clumps of the common frog Rana temporaria: number of ova and hatchability. British Journal of Herpetology 5:505-509.

Cooke, A. S. 1985. The deposition and fate of spawn clumps of the common frog Rana temporaria at a site in Cambridgeshire, 1971-1983. Biological Conservation 32:165-188.

Corn, P. S. 1998. Effects of ultraviolet radiation on boreal toads in Colorado. Ecological Applications 8:18-26.

Crouse, D. T., L. B. Crowder, and H. Caswell. 1987. A stage-based population model for loggerhead sea turtles and implications for conservation. Ecology 68:1412-1423.

Cummins, C. P. 1986. Temporal and spatial variation in egg size and fecundity in Rana temporaria. Journal of Animal Ecology 55:303-316.

Gibbons, M. M., and T. K. McCarthy. 1984. Growth, maturation and survival of frogs Rana temporaria L. Holarctic Ecology 7:419-427.

Gibbons, M. M., and T. K. McCarthy. 1986. The reproductive output of frogs Rana temporaria L. with particular reference to body size and age. Journal of Zoology, London 209:579-593.

Hemelaar, A. 1988. Age, growth and other population characteristics of Bufo bufo from different latitudes and altitudes. Journal of Herpetology 22:369-388.

Jones, M. S. 1998. Boreal toad research progress report 1998. Colorado Division of Wildlife, Denver, Colorado. 
Kagarise Sherman, C. 1980 A comparison of the natural history and mating system of two anurans: Yosemite toads (Bufo canorus) and black toads (Bufo exsul). Ph.D. Dissertation, University of Michigan, Ann Arbor, Michigan.

Licht, L. E. 1974. Survival of embryos, tadpoles, and adults of the frogs Rana aurora and Rana pretiosa sympatric in southwestern British Columbia. Canadian Journal of Zoology 52:613-627.

Loman, J. 1984. Density and survival of Rana arvalis and Rana temporaria. Alytes 3:125134.

Miaud, C., R. Guyétant, and J. Elmberg. 1999. Variations in life-history traits in the common frog Rana temporaria (Amphibia: Anura): a literature review and new data from the French Alps. Journal of Zoology, London 249:61-73.

Olson, D. H. 1992. Ecological susceptibility of amphibians to population declines. Pages 55-62 in R. R. Harris and D.E. Erman, technical coordinators, and H. M. Kerner, editor. Proceedings of a symposium on biodiversity of northwestern California. Report 29. University of California Wildland Resources Center, Davis, California.

Pettus, D., and G. M. Angleton. 1967. Comparative reproductive biology of montane and piedmont chorus frogs. Evolution 21:500-507.

Riis, N. 1991. A field study of survival, growth, biomass and temperature dependence of Rana dalmatina and Rana temporaria larvae. Amphibia-Reptilia 12:229-243.

Ryszkowski, L., and J. Truszkowski. 1975. Estimation of the abundance and biomass of transformed amphibians in a field pond. Bulletin of the Polish Academy of Sciences, Biological Sciences 23:109-113.

Seber, G. A. F. 1982. The estimation of animal abundance and related parameters. Second edition. Macmillan, New York. 
Sornborger, M. B. 1979. Population dynamics of the western toad, Bufo boreas halophilus, at Hidden Lake, Mt. San Jacinto State Park. Masters Thesis, California State Polytechnic University, Pomona, California.

Turner, F. B. 1960. Population structure and dynamics of the western spotted frog, Rana $p$. pretiosa Baird and Girard, in Yellowstone Park, Wyoming. Ecological Monographs 30:251-278.

Turner, F. B. 1962. The demography of frogs and toads. Quarterly Review of Biology $37: 303-314$

Worrest, R. C., and D. J. Kimeldorf. 1975. Photoreactivation of potentially lethal, UVinduced damage to boreal toad (Bufo boreas boreas) tadpoles. Life Science 17:15451550. 